Article

\title{
Assessing Light Pollution in China Based on Nighttime Light Imagery
}

\author{
Wei Jiang ${ }^{1,2}$, Guojin He ${ }^{1,3,4, *}$, Tengfei Long ${ }^{1,3,4}$, Chen Wang ${ }^{5}$, Yuan $\mathrm{Ni}^{1,6}$ and Ruiqi Ma ${ }^{7,8}$ \\ 1 Institute of Remote Sensing and Digital Earth, Chinese Academy of Sciences, Beijing 100094, China; \\ jiangwei@radi.ac.cn (W.J.); longtf@radi.ac.cn (T.L.); niyuanirsa@hotmail.com (Y.N.) \\ 2 University of the Chinese Academy of Sciences, Beijing 100049, China \\ 3 Key Laboratory of Earth Observation Hainan Province, Sanya 572029, China \\ Sanya Institute of Remote Sensing, Sanya 572029, China \\ 5 Satellite Environment Center, Ministry to Environmental Protection, Beijing 100094, China; \\ wangchen_ch@163.com \\ 6 Spatial Information Research Center of Fujian, Fuzhou University, Fuzhou 350002, China \\ 7 State Key Laboratory of Information Engineering in Surveying, Wuhan University, Wuhan 430079, China; \\ mrq_rs@163.com \\ 8 School of Lisiguang, China University of Geosciences, Wuhan 430074, China \\ * Correspondence: hegj@radi.ac.cn; Tel.: +86-10-8217-8190
}

Academic Editors: Xiaofeng Li, Bailang Yu and Prasad S. Thenkabail

Received: 19 November 2016; Accepted: 24 January 2017; Published: 6 February 2017

\begin{abstract}
Rapid urbanization and economic development inevitably lead to light pollution, which has become a universal environmental issue. In order to reveal the spatiotemporal patterns and evolvement rules of light pollution in China, images from 1992 to 2012 were selected from the Defense Meteorological Satellite Program Operational Linescan System (DMSP/OLS) and systematically corrected to ensure consistency. Furthermore, we employed a linear regression trend method and nighttime light index method to demonstrate China's light pollution characteristics across national, regional, and provincial scales, respectively. We found that: (1) China's light pollution expanded significantly in provincial capital cities over the past 21 years and hot-spots of light pollution were located in the eastern coastal region. The Yangtze River Delta, Pearl River Delta, and Beijing-Tianjin-Hebei regions have formed light pollution stretch areas; (2) China's light pollution was mainly focused in areas of north China (NC) and east China (EC), which, together, accounted for over $50 \%$ of the light pollution for the whole country. The fastest growth of light pollution was observed in northwest China (NWC), followed by southwest China (SWC). The growth rates of east China (EC), central China (CC), and northeast China (NEC) were stable, while those of north China (NC) and south China (SC) declined; (3) Light pollution at the provincial scale was mainly located in the Shandong, Guangdong, and Hebei provinces, whereas the fastest growth of light pollution was in Tibet and Hainan. However, light pollution levels in the developed provinces (Hong Kong, Macao, Shanghai, and Tianjin) were higher than those of the undeveloped provinces. Similarly, the light pollution heterogeneities of Taiwan, Beijing, and Shanghai were higher than those of undeveloped western provinces.
\end{abstract}

Keywords: light pollution; nighttime light; DMSP/OLS; nighttime light index; China

\section{Introduction}

Light pollution was first identified by astronomers in the 1930s [1]. Nowadays, it has become a widely discussed environmental issue following water pollution, air pollution, and noise pollution [2]. In $2001,19 \%$ of the global land area suffered from light pollution, which is higher than the threshold 
value, and $21 \%$ of the world's population are living in light-polluted environments [3]. At present, with the rapid urbanization and economic development around the world, light pollution is expanding at an unprecedented speed and to an unprecedented extent [2,4]. As the popularity of night lighting facilities is increasing, humans gradually expand the scope of their activities at night. However, studies have found that light pollution can also directly or indirectly affect animals [5-7] and ecological environments [8-11], human health [12-14], and astronomical observation [1,15]. Since the Chinese government implemented reform and the opening-up policy, unprecedented urbanization has taken place across the country, resulting in huge power consumption and a large number of cities with lights turned on all night. These places are referred to as 'sleepless cities'. Almost every large city has been threatened by light pollution due to the lack of policy guidance and regulations. However, the issue of China's light pollution has not yet been widely documented. Therefore, it is important to understand the evolution of rules regarding China's light pollution, in order to protect the ecological environment and to improve the quality of life for urban residents.

Traditional field surveys are costly, inefficient and difficult to compare with historical data. However, remote sensing using earth observation technology has the advantages of large scope, high frequency, and long time series. In particular, remote sensing technology focused on nighttime light can quickly generate regional and global satellite images of artificial light [16]. Historically, nighttime light remote sensing has been widely used in the fields of social and economic parameter estimation [17-26], urbanization monitoring [27-32], important event evaluation [33-35], and environment and health effects [36-38]. Light pollution is affected by many factors, including population and economic growth, nighttime light intensity, and atmospheric absorption $[39,40]$. Since nighttime light intensity can be directly observed by nighttime light remote sensing technology, a variety of studies have documented light pollution issues at regional and national scales by using nighttime light intensity as a proxy index [2-4,7,9,39-43]. Nighttime light imagery from satellite observation gives information on light pollution which represents not only the artificial light intensity, but also the other influencing factors, such as human activity intensity and the level of social and economic activity.

The Defense Meteorological Satellite Program Operational Linescan System (DMSL/OLS) provides the longest time series of nighttime light images in the world. Its use to map the world atlas of brightness in the artificial night sky was proven as early as in 2001 [3]. The result of that mapping showed that about two-thirds of the world's population lives in light-polluted areas, with the percentage of population in developed countries rising to 99\% [3]. Time-series DMSP/OLS nighttime light images and Geographic Information System (GIS) technologies were used to analyze light pollution and the results showed that suburban areas were experiencing serious light pollution during the rapid process of urbanization [39]. Nighttime light imagery was also applied to analyze light pollution in Pakistan, and the research demonstrated that the area of light pollution rapidly increased and the suburban areas were experiencing direct and indirect light pollution of artificial lights [40]. Bennie et al. proposed a novel method to analyze the trends of light pollution across the European continent and found that most countries with high economic levels were facing increasing light pollution; however, in other countries, including Hungary, Slovakia, Moldova, and Ukraine, the brightness of the light pollution was apparently decreasing [2]. Meanwhile, Han et al. employed the same method to investigate the trends of China's light pollution from 1992 to 2012. The research suggested that light pollution growth was mainly located in the eastern coastal cities, while a falling trend was observed in the industrial and mineral cities [41]. In order to investigate the relationship between light pollution and land use type, Kuechly et al. selected Berlin as the study area and confirmed that roads were the main source of light pollution at night [42]. Furthermore, ground investigation from different directions and high-spatial-resolution space-borne measurements were combined to understand the three dimensions of light pollution [43]. In terms of the further impact of light pollution, Kyba and Hoelker confirmed the effect of night-sky scattered light on ecosystems and biodiversity [44]. In addition, Bennie et al. evaluated global ecosystem types exposed to artificial light with the combined DMSP/OLS images and land cover products. They found that the Mediterranean 
climate ecosystem was most affected and that the global ecosystem has been localized and fragmented by artificial light [45].

In previous studies, light pollution has been explored in many regions, including Europe and China. However, these studies focused on light pollution trends using the mean value of different time series [41] and there is still a lack of a quantitative indicator methodology by which to measure light pollution. Although an intercalibration method has been used to process time series nighttime light imagery [2,41], the inter-annual and time series corrections have not been considered.

In this study, a systematic nighttime light calibration method was employed to improve the consistency and comparability of DMSP/OLS nighttime light series imagery, and then four nighttime light indices and linear regression methods were developed to analyze light pollution at national, regional, and provincial scales, respectively. These methods can provide a reference for light pollution in other regions, giving a research conclusion which can assist the government in objectively understanding China's light pollution process and, therefore, in making decisions on light pollution environmental issues.

\section{Materials and Methods}

\subsection{Study Area}

China is located in East Asia, situated on the Pacific West Coast, with a land area of about 9.6 million square kilometers. Since the economic reform in 1978, China's economy has sustained growth for almost 40 years, becoming the world's second largest economy in 2014 [46]. China also has the largest population, reaching over 1.3 billion in 2010 . More than half $(54.7 \%)$ of the Chinese population lived in the urban areas by the end of 2014, which has increased by $26 \%$ since 1990. Meanwhile, with the population shifting from rural to urban areas, cities have experienced unprecedented development [47]. Though China has made huge achievements over the past years, it faces serious and numerous environmental pollution issues. Unlike other pollution types, light pollution is seldom of high research interest in China; thus, it is necessary to further explore the spatiotemporal pattern of China's light pollution. According to the natural and socio-economic situation at the provincial scale, the study area was divided into seven regions (Figure 1).

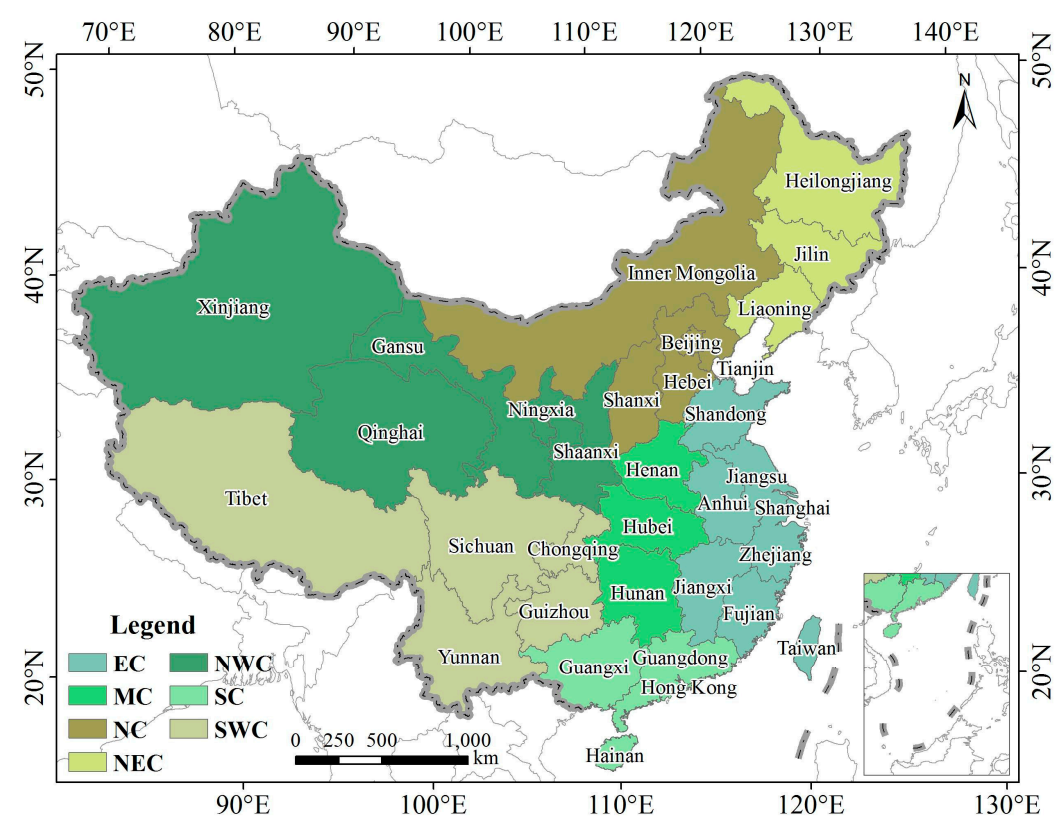

Figure 1. Seven regions of Chinese geography. EC: East China; CC: Central China; NC: North China; NEC: Northeast China; NWC: Northwest China; SC: South China; and SWC: Southwest China. 


\subsection{Nighttime Light Imagery}

Long-term time-series DMSP/OLS nighttime light satellite images from 1992 to 2012 were selected as the experimental data to study light pollution in China. DMSP/OLS began in the 1970s and its original purpose was to obtain the night cloud distribution information [48]. However, scientists found that DMSP/OLS could also capture the nighttime light from urban areas under cloudless conditions. The DMSP/OLS images in this study are version 4 and contain six sensors (Figure 2) which were downloaded from the National Geophysical Data Center (NGDC) website of National Oceanic and Atmospheric Administration (NOAA) [49]. The annual product of nighttime light contains the frequency of the cloud-free product, average light product, and stable nighttime light product, respectively. We selected 33 periods of global stable nighttime light product images as the study dataset, as it removed background noises, like gas flaring, wildlife fire, and aurora. Therefore, the brightness in imagery represents only the residential nighttime lights. This imagery consists of 30 arc-second grids, spanning from -180 to 180 degrees longitude and from -65 to 75 degrees latitude. The data pixel digital number $(\mathrm{DN})$ ranges from $0-63$ [50,51].

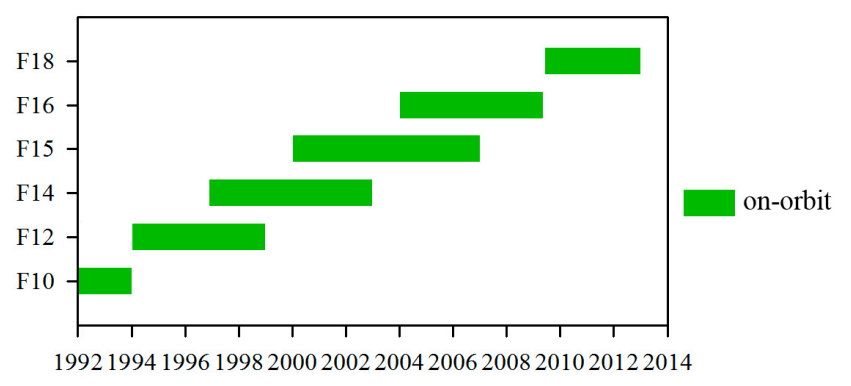

Figure 2. DMSP/OLS nighttime light time-series satellite.

\subsection{Nighttime Light Imagery Processing}

Since DMSP/OLS nighttime light images were acquired by six satellites (F10, F12, F14, F15 and F16) spanning 21 years without on-board calibration, it is necessary to correct nighttime light imagery to improve data comparability and accuracy [48]. In order to obtain a research dataset for studying, we have created a workflow to process the time-series nighttime light imageries (Figure 3), which includes three steps; namely, model establishment, image correction, and image post-processing.

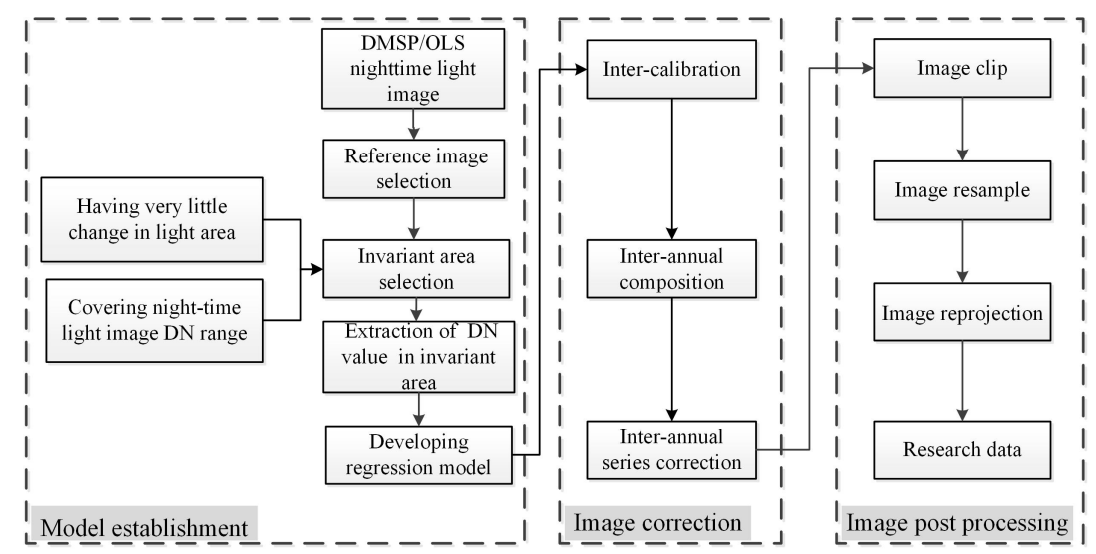

Figure 3. The process flow of DMSP/OLS nighttime light imagery.

\subsubsection{Model Establishment}

As six satellites without on-board calibration were used to generate the time series of nighttime light imagery from 1992 to 2012, these images are inconsistent in digital number (DN) values [48] and 
cannot be applied to perform comparative analysis directly [52,53]. Thus, development of a model is required to improve the image comparability. Elvidge et al. proposed an invariant area method which combines reference images to establish a long time series nighttime light model [54]. The invariant area is directly related to the performance of the model. According to this assumption, the invariant area has two conditions: (1) the socio-economic development in invariant area is a minimum, which ensures nighttime light levels show very little change; and (2) the invariant area should cover all of the gray levels of nighttime light images to ensure model universality. In Elvidge's method [54], Sicily in Italy was selected as an invariant area and scattergrams of the digital number values for each satellite versus F121999 were examined. Furthermore, a second order polynomial regression model was drawn from the scattergram, as follows:

$$
D N_{\text {ref }}=C_{0}+C_{1} \times D N_{t}+C_{2} \times D N_{t}^{2}
$$

where $D N_{\text {ref }}$ represents the pixel value of the reference image, $D N_{t}$ represents the pixel value of image in year $t$ and $C_{0}, C_{1}$ and $C_{2}$ represents the coefficients of regression model.

Through this model, $C_{0}, C_{1}$, and $C_{2}$ can be empirically derived and $R^{2}$ expresses the fitting degree of regression model. In this study, we directly employed coefficients of the Elvidge et al. [54] method and these coefficients and $R^{2}$ are shown in Table 1.

Table 1. Inter-calibration coefficients of DMSP/OLS.

\begin{tabular}{|c|c|c|c|c|c|}
\hline Satellite & Year & $C_{0}$ & $C_{1}$ & $C_{2}$ & $R^{2}$ \\
\hline F10 & 1992 & -2.0570 & 1.5903 & -0.0090 & 0.9075 \\
\hline F10 & 1993 & -1.0582 & 1.5983 & -0.0093 & 0.9360 \\
\hline F10 & 1994 & -0.3458 & 1.4864 & -0.0079 & 0.9243 \\
\hline F12 & 1994 & -0.6890 & 1.1770 & -0.0025 & 0.9071 \\
\hline F12 & 1995 & -0.0515 & 1.2293 & -0.0038 & 0.9178 \\
\hline F12 & 1996 & -0.0959 & 1.2727 & -0.0040 & 0.9319 \\
\hline F12 & 1997 & -0.3321 & 1.1782 & -0.0026 & 0.9245 \\
\hline F12 & 1998 & -0.0608 & 1.0648 & -0.0013 & 0.9536 \\
\hline F12 & 1999 & 0.0000 & 1.0000 & 0.0000 & 1.0000 \\
\hline F14 & 1997 & -1.1323 & 1.7696 & -0.0122 & 0.9101 \\
\hline F14 & 1998 & -0.1917 & 1.6321 & -0.0101 & 0.9723 \\
\hline F14 & 1999 & -0.1557 & 1.5055 & -0.0078 & 0.9717 \\
\hline F14 & 2000 & 1.0988 & 1.3155 & -0.0053 & 0.9278 \\
\hline F14 & 2001 & 0.1943 & 1.3219 & -0.0051 & 0.9448 \\
\hline F14 & 2002 & 1.0517 & 1.1905 & -0.0036 & 0.9203 \\
\hline F14 & 2003 & 0.7390 & 1.2416 & -0.0040 & 0.9432 \\
\hline F15 & 2000 & 0.1254 & 1.0452 & -0.0010 & 0.9320 \\
\hline F15 & 2001 & -0.7024 & 1.1081 & -0.0012 & 0.9593 \\
\hline F15 & 2002 & 0.0491 & 0.9568 & 0.0010 & 0.9658 \\
\hline F15 & 2003 & 0.2217 & 1.5122 & -0.0080 & 0.9314 \\
\hline F15 & 2004 & 0.5751 & 1.3335 & -0.0051 & 0.9479 \\
\hline F15 & 2005 & 0.6367 & 1.2838 & -0.0041 & 0.9335 \\
\hline F15 & 2006 & 0.8261 & 1.2790 & -0.0041 & 0.9387 \\
\hline F15 & 2007 & 1.3606 & 1.2974 & -0.0045 & 0.9013 \\
\hline F16 & 2004 & 0.2853 & 1.1955 & -0.0034 & 0.9039 \\
\hline F16 & 2005 & -0.0001 & 1.4159 & -0.0063 & 0.9390 \\
\hline F16 & 2006 & 0.1065 & 1.1371 & -0.0016 & 0.9199 \\
\hline F16 & 2007 & 0.6394 & 0.9114 & 0.0014 & 0.9511 \\
\hline F16 & 2008 & 0.5564 & 0.9931 & 0.0000 & 0.9450 \\
\hline F16 & 2009 & 0.9492 & 1.0683 & -0.0016 & 0.8918 \\
\hline F18 & 2010 & 2.3430 & 0.5102 & 0.0065 & 0.8462 \\
\hline F18 & 2011 & 1.8956 & 0.7345 & 0.0030 & 0.9095 \\
\hline F18 & 2012 & 1.8750 & 0.6203 & 0.0052 & 0.9392 \\
\hline
\end{tabular}




\subsubsection{Image Correction}

(1) Inter-calibration

According to the inter-calibration coefficients of Table 1, each image in this study was inter-calibrated by band math using the ENVI 4.8 software and the DN values below 0 were assigned to 0 , while DN above 63 were assigned to 63.

(2) Inter-annual composition

In the same year, two kinds of sensors were used to obtain the nighttime light images, for example, F12 and F14. In order to make full use of information from multiple sensors, the inter-calibration images needed to be inter-annual composited [55]. The formula is as follows:

$$
\begin{gathered}
D N_{(n, t)}=\left\{\begin{array}{cc}
0 & D N_{(n, t)}^{a}=0 \text { and } D N_{(n, t)}^{b}=0 \\
\text { other } & \left(D N_{(n, t)}^{a}+D N_{(n, t)}^{b}\right) / 2
\end{array}\right. \\
t=1994,1997,1998, \ldots 2007
\end{gathered}
$$

where $D N_{(n, t)}^{a}$ and $D N_{(n, t)}^{b}$, respectively, represent the image $D N$ values of sensor a and sensor $b$ at the pixel $n$ after the inter-calibration in year $t, D N_{(n, t)}$ represent image $D N$ values at the pixel $n$ after the inter-annual composition in year $t$.

(3) Inter-annual series correction

Over the past 20 years, most cities in China have experienced continuous expansion. It can be assumed that $D N$ values in the latter year should be no less than that seen in the previous year in the same position. Thus, the inter-annual series correction method was employed to calibrate time-series of nighttime light images [53,56]. The calibration can be divided into the following cases: (1) If the $D N$ value is 0 in the latter year, it should be 0 in the previous year; (2) when the $D N$ value is above 0 , the $D N$ value in the previous year should be less than that in the latter year; and (3) in other cases, the image $D N$ value remains the same [56]. Based on this principle, the correction formula is as follows:

$$
\begin{gathered}
D N_{(n, t)}=\left\{\begin{array}{cc}
0 & D N_{(n, t+1)}=0 \\
D N_{(n, t-1)} & D N_{(n, t+1)}>0 \text { and } D N_{(n, t-1)}>D N_{(n, t)} \\
D N_{(n, t)} & \text { other }
\end{array}\right. \\
n=1992,1993, \ldots, 2012
\end{gathered}
$$

where $D N_{(n, t-1)}, D N_{(n, t)}$ and $D N_{(n, t+1)}$, respectively, represent the $D N$ value of pixel $\mathrm{n}$ after inter-annual composition in year $t-1$, year $t$, and year $t+1$.

\subsubsection{Post-Image Processing}

The study area image was clipped from the global image according to the 1:250,000 administrative boundaries of China, and resampled at $1 \mathrm{~km}$ resolution. Those images were reprojected to the Albers equal area conic projection with the 1940 Krassovsky ellipsoid and a dataset was generated for this research.

\subsection{Method}

\subsubsection{Linear Regression Trend Method}

A linear regression trend method can be used to compute the changing trends of each pixel during the study period $[57,58]$. It is possible to comprehensively reveal the spatial temporal pattern through the changes in the trends characteristic of each pixel, [59,60]. With the advantage of eliminating DN 
outliers by fitting time-series DN values, this method can objectively reveal temporal change trends of light pollution. The calculation formula is as follows:

$$
\text { slope }=\frac{\mathrm{t} \times \sum_{i=1}^{t} i \times D N_{i}-\sum_{i=1}^{t} i \sum_{i=1}^{t} D N_{i}}{\mathrm{t} \times \sum_{i=1}^{t} i^{2}-\left(\sum_{i=1}^{t} i\right)^{2}}
$$

where $D N_{i}$ represents the $\mathrm{DN}$ value in year $i, t$ represents time span ( $t=21$ years in this study). If slope $>0$, it represents an increase of light pollution and the higher the slope value, the more significant the increase; if slope $<0$, it represents a decline of light pollution and the lower the slope value, the more significant the decline; otherwise, slope $=0$ means the light pollution is stable.

\subsubsection{Construction of the Nighttime Light Index}

In order to analyze the spatial and temporal characteristics of light pollution, four nighttime light indices were constructed, including total night light (TNL), night light mean (NTM), night light standard deviation (NTSD), and the proportion of total night light (PTNL). TNL, NTM, and NTSD index values were extracted using ArcGIS 10. The formulas and descriptions of the indices value are shown in Table 2.

Table 2. Nighttime light indices.

\begin{tabular}{lll}
\hline Indicator Name & Expression & $\begin{array}{l}\text { Description } \\
\text { Total night light (TNL) }\end{array} \quad \begin{array}{l}\text { Refers to the total amount level of light } \\
\text { pollution in the statistical area. } D N_{i} \text { is the } \\
\text { ith gray level, } C_{i} \text { is the number of pixels that } \\
\text { correspond to the gray level. }\end{array}$ \\
\hline Night light mean (NTM) & $N T M=\left(\sum_{i=1}^{63} C_{i} \times D N_{i}\right) / \sum_{i=1}^{63} C_{i}$ & $\begin{array}{l}\text { Refers to the average level of light pollution } \\
\text { in the statistical area. } D N_{i} \text { is the } i \text { th gray } \\
\text { level, } C_{i} \text { is the number of pixels } \\
\text { corresponding to the gray level. }\end{array}$ \\
\hline $\begin{array}{l}\text { Night light standard } \\
\text { deviation (NTSD) }\end{array}$ & $N T S D=\sqrt{\frac{1}{N} \sum_{i=1}^{N}\left(D N_{i}-N T M\right)^{2}}$ & $\begin{array}{l}\text { Refers to the differentiation level of light } \\
\text { pollution in the statistical area. } D N_{i} \text { is the } \\
\text { ith gray level, NTM is the night light mean. }\end{array}$ \\
\hline $\begin{array}{l}\text { Proportion of total night } \\
\text { light (PTNL) }\end{array}$ & $\begin{array}{l}\text { Refers to the proportion of TNL in each } \\
\text { region to that of the whole country. TNL is } \\
\text { the total night light in the region and TNL } \\
\text { is the total night light in the whole region. }\end{array}$ \\
\hline
\end{tabular}

\section{Results}

\subsection{Comparison of Night Light Image Correction}

In order to evaluate the effect of nighttime light image correction, the TNL of China was extracted before and after correction (Figure 4). The TNLs of different sensors among original images (Figure 4a) show significant differences in the same year. However, after the inter-calibration (Figure $4 \mathrm{~b}$ ), the TNL is more consistent in different years, and the result shows that the sensor error was effectively eliminated. Furthermore, the inter-annual composition method was employed to correct the images and Figure 4c shows that the annual fluctuation of TNL is an increasing trend during the study year. Consequently, the inter-annual series correction method was used to correct the images and the correction result is shown in Figure $4 \mathrm{~d}$. After the inter-annual series correction was applied, the increasing trend of TNL was more stable. This indicates that the image correction has a good performance and it can, therefore, be used to analyze the spatial and temporal characteristics of night light pollution in China. 



Figure 4. TNL of nighttime light images before and after correction. (a) Original images; (b) inter-calibration; (c) inter-annual composition; and (d) inter-annual series correction.

\subsection{Night Light Pollution Variation Characteristics at the National Scale}

A linear regression trend method was employed to reveal the variation characteristics of light pollution in China from 1992 to 2012, as shown in Figure 5. The figure shows that light pollution experienced a sharply increasing trend at the national level. Light-polluted areas were mainly located in municipalities and provincial capitals, whereas local areas showed a declining trend, for example in Shanxi, Yunnan, Inner Mongolia, and Xinjiang Province. In addition, in most areas of China, light pollution showed a stable trend. This stable trend contains two cases: urban area stable light pollution and rural area stable light pollution. The former case is mainly due to light pollution in urban core areas being high in 1992 and it remained stably sustained from 1992 to 2012; thus, the change trend of light pollution was stable. The latter case is mainly because there is almost no human activity at night in the rural areas; thus, these areas sustained no light pollution during the past 21 years. Generally, light pollution in China is located in three major urban agglomerations (the Beijing-Tianjin-Hebei region, the Yangtze River Delta, and the Pearl River Delta) and light pollution around the middle Yangtze, the Shandong Peninsula, Chengdu-Chongqing, and Harbin-Changchun is also at a high level.

In order to investigate light pollution in the three major urban agglomerations (the Beijing-Tianjin-Hebei region, the Yangtze River Delta, and the Pearl River Delta), the synthesis map (Figure 6) was generated by using multi-temporal (1992, 2012, and 2012) nighttime light imagery. The black color represents stable light pollution from 1992 to 2012, the red color represents extended light pollution, and the blue color represents decreasing light pollution, respectively.

Compared to the Pearl River Delta and the Beijing-Tianjin-Hebei region, the composite color around the Yangtze River Delta is white and red from Shanghai to Nanjing. Therefore, it demonstrates that the Yangtze River Delta experienced rapid and wide increases in light pollution along the Yangtze River. From the spatial pattern of light pollution, it can be clearly seen that the Yangtze River Delta has formed a light pollution stretch area from Shanghai to Nanjing (Figure 6b). In addition, Hangzhou and Ningbo also experienced increasing light pollution. 




Figure 5. Change trend of nighttime light pollution in China (red color represents a light pollution increase, blue color represents a light pollution decrease, and black color represents stable light pollution).
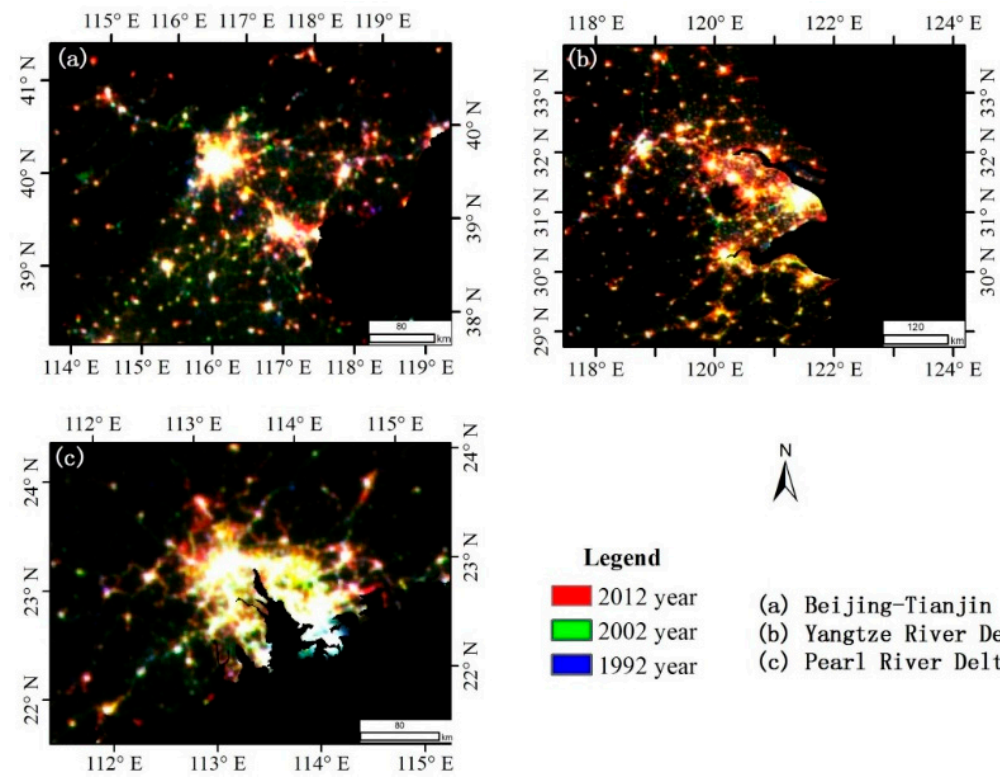
(a) Beijing-Tianjin
(b) Yangtze River Delta
(c) Pear1 River Delta

Figure 6. Color composite of nighttime light of three major urban agglomerations in China. (a) The Beijing-Tianjin-Hebei region; (b) the Yangtze River Delta; and (c) the Pearl River Delta.

The most light-polluted cities (Guangzhou, Dongguan, Shenzhen, Hong Kong, Macao, Zhuhai, and Foshan) are shown in the white color in Figure 6c. This result indicates that light pollution in the Pearl River Delta formed a stretch zone from 1992 to 2012 and this stretch zone is more stable than the one in the Yangtze River Delta. In addition, light pollution in Hong Kong showed a decreasing trend, which may relate to Hong Kong's light pollution policy in recent years [61]. Compared with the Yangtze River Delta and the Pearl River Delta, the spatial connectivity of light pollution in the Beijing-Tianjin-Hebei urban agglomerations are less obvious.

During the past 21 years, China's light pollution has had an expanding trend (Figure 5). However, areas of light pollution decline still exist, which are represented by the blue color in Figure 5. In order to analyze the reasons for the decrease of nighttime light, high-resolution satellite images from Google 
Earth were selected to validate the land cover type, with results shown in Figure 7. Figure 7A,B represent abandoned oil mining facilities; Figure 7C-E represent abandoned coal mining facilities; and Figure 7F,G represent dam construction facilities. It was found that the main drivers of light pollution decrease were facilities abandoned due to resource exploitation and the completion of the dam project. Gas flaring phenomena occurred in the process of oil exploration. Elvidge et al. demonstrated that DMSP/OLS can be used to monitor gas flaring [52]. In the gas flaring areas, the gray values of nighttime light imagery are close to the urban core gray values, and even more saturated. When the oil exploration decreased, the gray values of the image corresponding to the gas flaring areas decreased significantly and the regression change analysis shows a downward trend. The main reason for the light pollution decrease in the Shanxi, Shaanxi, and Inner Mongolia Province regions is that coal exploitation weakened or was exhausted, resulting in decreasing population and economic activities surrounding the mine. This caused a decrease in the nighttime light pollution. The decline in nighttime light pollution in Yunnan was mainly due to dam construction. During the construction process, high-power searchlights were used, resulting in strong light pollution. When the project was completed, the searchlights were no longer required and the nighttime light intensity decreased, leading to a decreasing trend in the light pollution change.
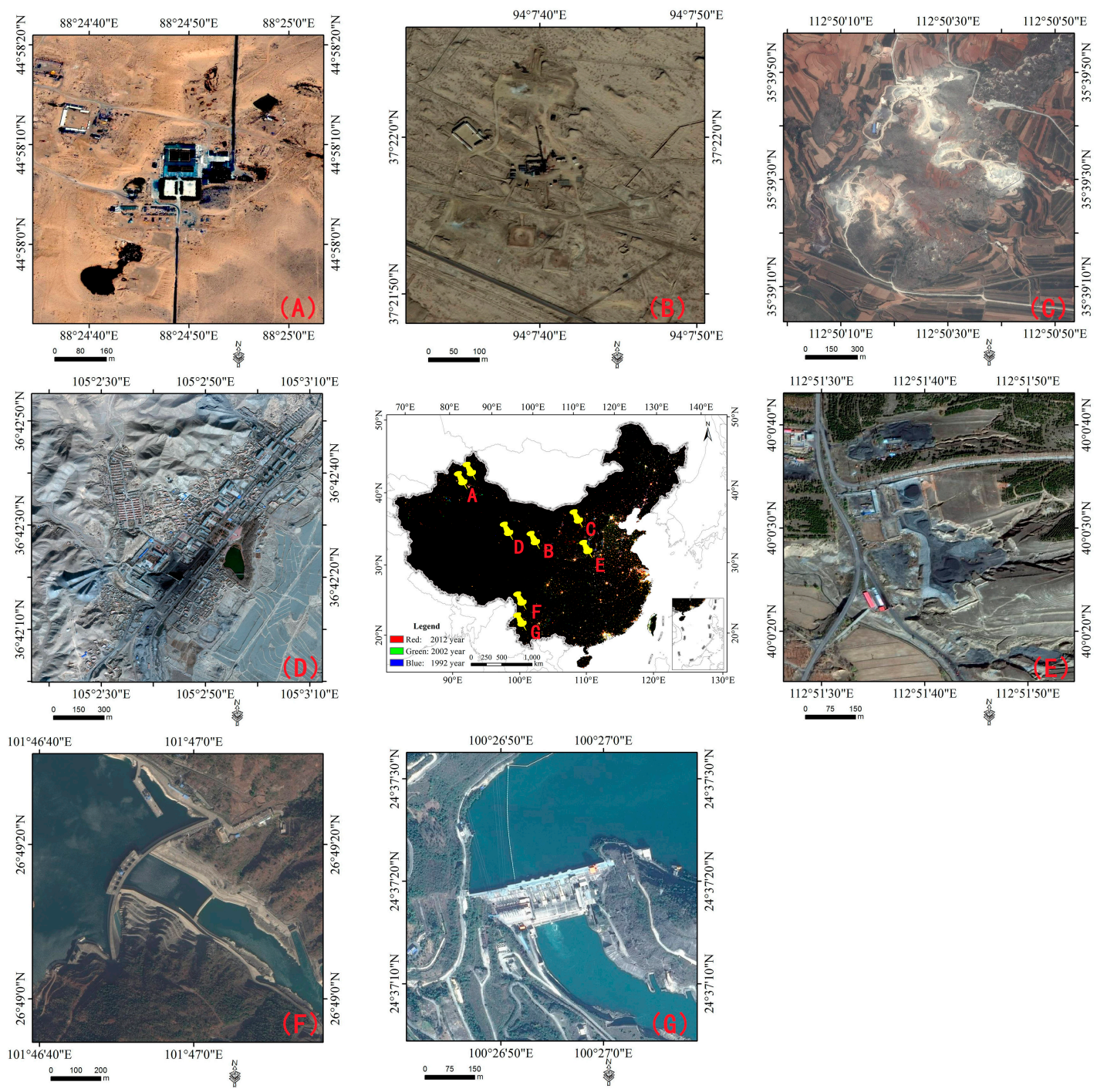

Figure 7. Validation of the nighttime light pollution decline regions $((\mathbf{A}, \mathbf{B})$ represent oil mining abandoned facilities; (C-E) represent coal mining abandoned facilities; and $(\mathbf{F}, \mathbf{G})$ represent dam construction facilities). 


\subsection{Night Light Pollution Change Characteristics at the Regional Scale}

In order to understand the changing characteristics of light pollution on a regional scale in China, the TNL and PTNL indices were employed. The result is shown in Figure 8. The TNL in seven regions showed an increasing trend from 1992 to 2012. The largest growth range of TNL was seen in east China, followed by north China, and the smallest growth range of TNL was observed in south China. This is because east China includes five coastal provinces and Shanghai, so the economic level of this region is higher than the national average. North China consists of a large industrial zone and is also a densely populated area of China. Overall, the sum of TNL in east China and north China accounted for half of the TNL. Although Guangdong Province is located in south China and it is highly economically developed, the economic development level of the Guangxi and Hainan provinces are lower than the national average. The fastest growth rate of TNL was in southwest China, followed by northwest China. Southwest China witnessed an increase of 340\% and northwest China, 290\%. The growth rates of these regions were higher than those of east China and north China. This is understandable because western cities have enjoyed rapid development since the launch of the Western Development Strategy. It also demonstrates that nighttime light pollution will inevitably increase during rapid social and economic development.

As shown in Figure 8, the TNL in east China accounted for about 30\% of the TNL of the whole country, followed by north China, accounting for about $20 \%$, and southwest China, which accounted for only $6 \%$ of the whole country. Thus, light pollution has a significant spatial imbalance around the country. Furthermore, each region shows a difference in PTNL trends. According to the statistical results shown in Figure 8, the inter-annual change trends of PTNL can be divided into three types: increasing (northwest China and southwest China), decreasing (north China and south China), and stable (east China, central China, and northeast regions). The increasing pattern shows that the light pollution is accelerating, and the growth rate of TNL is higher than that of the national average. This result demonstrated that light pollution has expanded and intensified over the past 21 years. The iron and steel industry production decline may be related to the PTNL decline in north China. However, the decrease of PTNL in south China may be related to the lower speed of economic growth in Guangxi and Hainan. The stable pattern shows that the speed of light pollution expansion is relatively consistent with that of the national average, and there are fluctuations. During the study years, the fluctuation of PTNL in east China was stable; however, the PTNL in central China first increased and then decreased. Conversely, the PTNL in northeast China first decreased, and then increased.
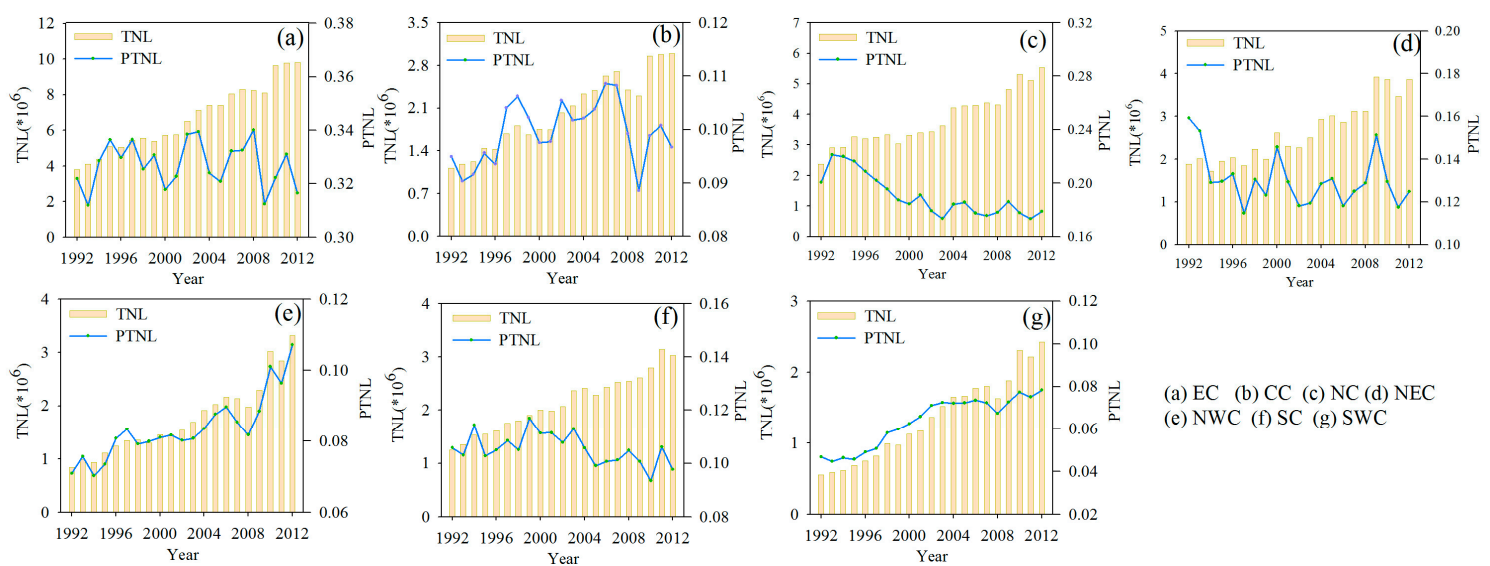

Figure 8. Nighttime light pollution at the regional scale in China. (a) EC; (b) CC; (c) NC; (d) NEC; (e) NWC; (f) SC; (g) SWC. 


\subsection{Night Light Pollution Change Characteristics at the Provincial Scale}

The night light pollution characteristics of 34 provincial administrative regions (including Hong Kong, Macao, and Taiwan) in China were analyzed by using the total of night light (TNL), the mean of night light (MNL) and the standard deviation of night light (SDNL). Figure 9 shows the statistical results of the total value of night light in each province of China. It can be seen from the figure for the TNL index that the three provinces showing the highest figures are Shandong, Guangdong, and Hebei. The lowest three figures correspond to Hong Kong, Tibet, and Macao. The results indicate that the TNL is not only related to the level of economic development, but also to the administrative area. The largest night light pollution was found in Shandong, Guangdong, Hebei, which have higher economic development levels and have a wider area. The TNL in Hong Kong declined by $11.1 \%$, which is related to the government's prevention and control measures for light pollution in recent years. The TNL in other provinces showed an upward trend, which indicated that light pollution in the night also showed an increasing trend. Among those provinces, Tibet had the fastest growth rate, which was $768 \%$. Hainan Province increased by $462 \%$. Beijing and Shanghai increased by $68 \%$ and $71 \%$, respectively. These results show that night light pollution has risen rapidly in economically undeveloped provinces and this result mainly relates to the rapid increase of government investment. On the contrary, the growth of TNL was slower in the more economically developed areas.

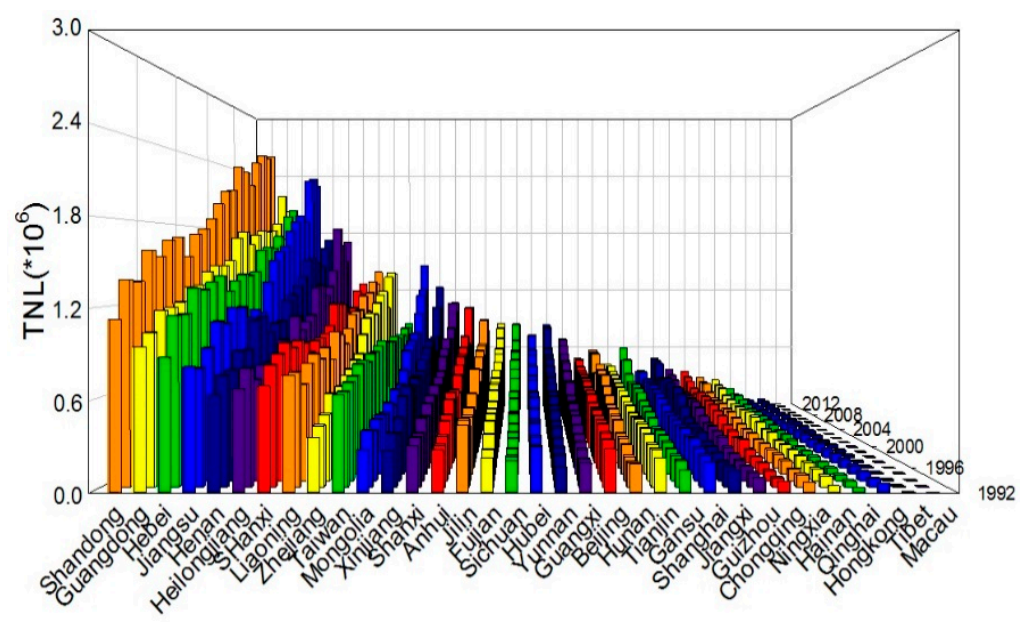

Figure 9. Total nighttime light (TNL) at the provincial scale in China.

Compared with the TNL, the MNL can eliminate the influence of the administrative area and reflect the regional average night light pollution level. The average statistical results of nighttime light in each province of China are shown in Figure 10. For the MNL, the top three are Hong Kong, Macao, and Shanghai, the lowest three are in Xinjiang, Qinghai, and Tibet. This suggests that the nighttime light pollution level is associated with economic development. Hong Kong, Macao and Shanghai are often known as the "sleepless cities", with MNL digital numbers ranging from 20 to 50 . Most of the undeveloped provinces belong to the non-luminous areas, and have a low degree of nighttime light pollution. The fastest growth rate of the MNL was seen in Tibet, followed by Hainan, while the growth rate of more economically developed cities was low. Hong Kong had a negative MNL growth, which is consistent with the changing of the TNL value. Light pollution increased considerably in Shanghai, Tianjin, and Jiangsu and the growth of MNL among these provinces was more than 10. Hong Kong and Macau had smaller increases, because Hong Kong and Macao have a small land area and higher economic level; thus, their light pollution is more serious. In Shanghai, Tianjin, and Jiangsu, light pollution has become an increasingly serious problem due to long-term economic development. 


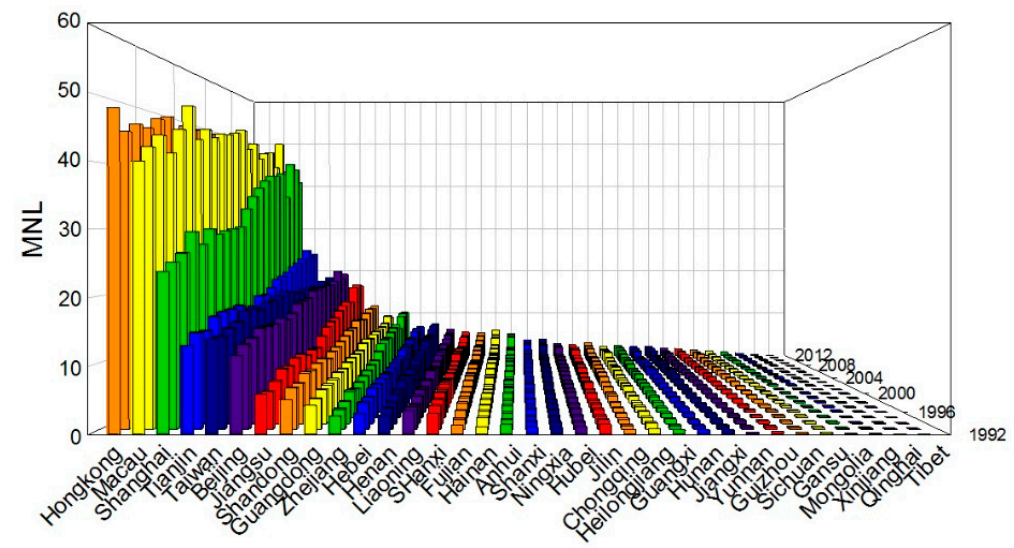

Figure 10. Mean nighttime light (MNL) at the provincial scale in China.

The standard deviation of night lights (SDNL) can reflect regional heterogeneities. The SDNLs in different provinces of China are shown in Figure 11. The SDNLs of Taiwan, Beijing, and Shanghai were higher, while in Xinjiang, Qinghai, and Tibet they were relatively lower. This result shows that light pollution in the developed areas has a greater heterogeneity. This is because MNL in the developed province has a high value, but the gray value in the suburbs (non-luminous) is zero, resulting in greater heterogeneities across the whole region. For undeveloped provinces, the MNL is low in most of the areas in the dark, so the nighttime light pollution is less heterogeneous across the whole region. Most provinces witnessed an SDNL increase during the past year, except for Macao, whose SDNL dropped by $10.3 \%$. The SDNL of Tibet had the fastest growth of up to $219 \%$, followed by Yunnan, with $156 \%$. These results show that the light pollution imbalance among undeveloped provinces increased during the study years.

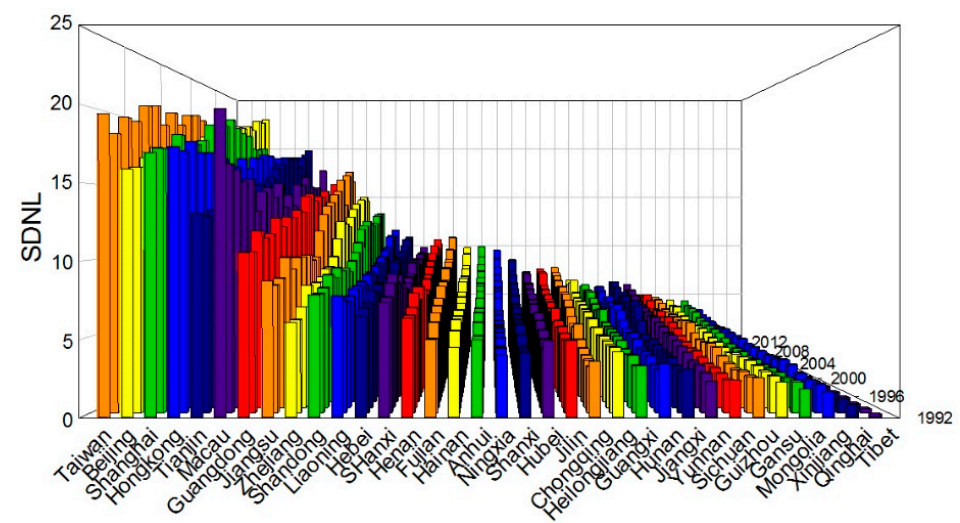

Figure 11. Standard deviation nighttime light (SDNL) at the provincial scale in China.

\section{Discussion}

Currently, light pollution has become a global environmental issue, especially in developed countries [2] and rapidly developing countries [38-40]. A typical case is China, which has experienced unprecedented urbanization and achieved remarkable economic development during the past three decades. The light pollution trends in China have been reported in a previous study [40] using time-series DMSP/OLS imagery; however, this strategy still lacks quantitative indicator methods to measure light pollution. In addition, the processes and patterns of light pollution in China are not clear over different scales, as a result of the huge imbalance between the east and west in China's social and economic development. In this study, we employed a systematic nighttime light calibration flow to improve the consistency and comparability of DMSP/OLS time series imagery. In addition to the 
widely used TNL index, we also developed three nighttime light indices to quantitatively assess the light pollution across the national, regional, and provincial scales, respectively.

The increasing trend of light pollution at the national scale is consistent with the previous study [40]. Moreover, we found that the Yangtze River Delta, the Pearl River Delta and the Beijing-Tianjin-Hebei urban agglomeration have formed a light pollution stretch area and the spatial connectivity of light pollution in the Yangtze River Delta and Pearl River Delta is more obvious than that of the Beijing, Tianjin, and Hebei urban agglomeration. This result is consistent with the findings described by Yu et al. [30] from urban spatial cluster analysis with DMSP-OLS nighttime light data. When considering declining areas of light pollution, we found similar decreasing trends in cities with rich mineral resources as shown in previous studies [2,40], such as the Shanxi, Shaanxi, and Inner Mongolia provinces. We further found that light pollution in regions with oil mining and dam construction facilities has been decreasing during the past 21 years.

At the regional scale, light pollution across east China and north China was higher than in west China, and the first two regions account for about $50 \%$ of the TNL in the whole country. However, the growth rate of light pollution in northwest China and southwest China is accelerating. These findings can be linked with economic development trends and policy guidance in China, for example the Western Development Strategy.

At the provincial scale, three nighttime light indices were used to assess the nighttime light pattern and these indicators can effectively reflect the overall level, average level, and difference level of light pollution. With those results, it is more objective and accurate to reveal the past, present, and trends of light pollution levels in China. In addition, we also found that the light pollution level can be linked with the social and economic development level; thus, these nighttime light indicators can be used to further estimate socio-economic parameters.

\section{Conclusions}

In order to analyze the characteristics of the light pollution in China, this paper proposes a process flow to correct the time series DMSP/OLS nighttime light imagery from 1992 to 2012. Following this process, a linear regression trend method and nighttime light index were employed to discover the temporal and spatial characteristics of light pollution at multiple scales. The conclusions of this study are as follows:

(1) After image correction, time series DMSP/OLS nighttime light imagery errors can be eliminated efficiently. This improved the consistency of the image and laid the foundations for the light pollution analysis.

(2) Areas of light pollution increase were mainly located in municipalities and capital cities and found in the Yangtze River Delta, the Pearl River Delta, and the Beijing-Tianjin-Hebei region stretching area. Due to resource depletion and the dam construction project, local-area light pollution showed a decrease in the Shanxi, Inner Mongolia, Shaanxi, Xinjiang, and Yunnan provinces.

(3) The TNLs of seven regions showed an increasing trend over the previous year. The largest growth range of the TNL was in east China, followed by north China. The fastest growth rate of the TNL was in southwest China (increased by $340 \%$ ), followed by northwest China (increased by $290 \%$ ). According to PTNL change trends, northwest China and southwest China were increased, north China and south China were decreased, and east China, central China, and the northeast regions were stable.

(4) The greatest level of TNL was located in Shandong at the provincial scale, followed by Guangdong and Hebei. The high levels of light pollution were mainly located in the developed provinces (Hong Kong, Macao, Shanghai, and Tianjin). In Tibet and Hainan, the TNL growth has been very rapid. The light pollution heterogeneities of developed provinces (Taiwan, Beijing, and Shanghai) were high; however, those of undeveloped provinces (Xinjiang, Qinghai, and Tibet) were low. The growth rate of the SDNL of the western provinces was higher than that of the east provinces. 
In this study, DMSP/OLS nighttime light remote sensing was used to demonstrate the temporal and spatial characteristics of China's light pollution at multiple scales. It is helpful to objectively and accurately understand the light pollution problems of the recent rapid urbanization. Moreover, this conclusion can be of benefit to the government for policy-making and light pollution regulation. For the next step, we will further research nighttime light pollution's effect on the ecological environment and risks to health by integrating multi-source remote sensing data and ground investigation data.

Acknowledgments: The DMSP/OLS nighttime light imagery was downloaded from the NOAA website. This research was financially supported by The National Key Research and Development Program of China-rapid production method of large scale global change products (2016YFA0600302), the Hainan Provincial Department of Science and Technology under Grant Nos. ZDKJ2016021 and ZDKJ2016015 and the National Natural Science Funds of China (41501116). The authors thank editors and three anonymous reviewers for their valuable comments to improve our manuscript and also would like to thank Phillipa Simpson for proofreading this paper.

Author Contributions: G.H. and W.J. conceived and designed the experiments; W.J. and R.M. performed the experiments; W.J. and T.L. analyzed the data; C.W. and Y.N. contributed reagents/materials/analysis tools; W.J. wrote the paper.

Conflicts of Interest: The authors declare no conflict of interest.

\section{References}

1. Riegel, K.W. Light pollution. Science 1973, 179, 1285-1291. [CrossRef] [PubMed]

2. Bennie, J.; Davies, T.W.; Duffy, J.P.; Inger, R.; Gaston, K.J. Contrasting trends in light pollution across Europe based on satellite observed night time lights. Sci. Rep. 2014, 4. [CrossRef] [PubMed]

3. Cinzano, P.; Falchi, F.; Elvidge, C.D. The first world atlas of the artificial night sky brightness. Mon. Not. R. Astron. Soc. 2001, 328, 689-707. [CrossRef]

4. Falchi, F.; Cinzano, P.; Duriscoe, D.; Kyba, C.C.M.; Elvidge, C.D.; Baugh, K.; Portnov, B.A.; Rybnikova, N.A.; Furgoni, R. The new world atlas of artificial night sky brightness. Sci. Adv. 2016, 2, e1600377. [CrossRef] [PubMed]

5. Raap, T.; Pinxten, R.; Eens, M. Light pollution disrupts sleep in free-living animals. Sci. Rep. 2015, 5, 13557. [CrossRef] [PubMed]

6. Gaston, K.J.; Visser, M.E.; Hoelker, F. The biological impacts of artificial light at night: The research challenge. Philos. Trans. R. Soc. B Sci. 2015, 370. [CrossRef] [PubMed]

7. Mazor, T.; Levin, N.; Possingham, H.P.; Levy, Y.; Rocchini, D.; Richardson, A.J.; Kark, S. Can satellite-based night lights be used for conservation? The case of nesting sea turtles in the mediterranean. Biol. Conserv. 2013, 159, 63-72. [CrossRef]

8. Gaston, K.J.; Bennie, J.; Davies, T.W.; Hopkins, J. The ecological impacts of nighttime light pollution: A mechanistic appraisal. Biol. Rev. 2013, 88, 912-927. [CrossRef] [PubMed]

9. Rodriguez, A.; Rodriguez, B.; Negro, J.J. GPS tracking for mapping seabird mortality induced by light pollution. Sci. Rep. 2015, 5, 10670. [CrossRef] [PubMed]

10. Kamrowski, R.L.; Sutton, S.G.; Tobin, R.C.; Hamann, M. Balancing artificial light at night with turtle conservation? Coastal community engagement with light-glow reduction. Environ. Conserv. 2015, 42, 171-181. [CrossRef]

11. Rodriguez, A.; Garcia, D.; Rodriguez, B.; Cardona, E.; Parpal, L.; Pons, P. Artificial lights and seabirds: Is light pollution a threat for the threatened balearic petrels? J. Ornithol. 2015, 156, 893-902. [CrossRef]

12. Kloog, I.; Haim, A.; Stevens, R.G.; Portnov, B.A. Global co-distribution of light at night (lan) and cancers of prostate, colon, and lung in men. Chronobiol. Int. 2009, 26, 108-125. [CrossRef] [PubMed]

13. Koo, Y.S.; Song, J.-Y.; Joo, E.-Y.; Lee, H.-J.; Lee, E.; Lee, S.-K.; Jung, K.-Y. Outdoor artificial light at night, obesity, and sleep health: Cross-sectional analysis in the koges study. Chronobiol. Int. 2016, 33, 301-314. [CrossRef] [PubMed]

14. Parent, M.-E.; El-Zein, M.; Rousseau, M.-C.; Pintos, J.; Siemiatycki, J. Night work and the risk of cancer among men. Am. J. Epidemiol. 2012, 176, 751-759. [CrossRef] [PubMed]

15. Cinzano, P.; Falchi, F.; Elvidge, C.D.; Baugh, K.E. The artificial night sky brightness mapped from DMSP satellite operational linescan system measurements. Mon. Not. R. Astron. Soc. 2000, 318, 641-657. [CrossRef] 
16. Elvidge, C.D.; Cinzano, P.; Pettit, D.R.; Arvesen, J.; Sutton, P.; Small, C.; Nemani, R.; Longcore, T.; Rich, C.; Safran, J.; et al. The nightsat mission concept. Int. J. Remote Sens. 2007, 28, 2645-2670. [CrossRef]

17. Sutton, P.; Roberts, D.; Elvidge, C.; Baugh, K. Census from heaven: An estimate of the global human population using night-time satellite imagery. Int. J. Remote Sens. 2001, 22, 3061-3076. [CrossRef]

18. Chen, X.; Nordhaus, W.D. Using luminosity data as a proxy for economic statistics. Proc. Natl. Acad. Sci. USA 2011, 108, 8589-8594. [CrossRef] [PubMed]

19. He, C.Y.; Ma, Q.; Li, T.; Yang, Y.; Liu, Z.F. Spatiotemporal dynamics of electric power consumption in Chinese mainland from 1995 to 2008 modeled using dmsp/ols stable nighttime lights data. J. Geogr. Sci. 2012, 22, 125-136. [CrossRef]

20. Asefi-Najafabady, S.; Rayner, P.J.; Gurney, K.R.; McRobert, A.; Song, Y.; Coltin, K.; Huang, J.; Elvidge, C.; Baugh, K. A multiyear, global gridded fossil fuel $\mathrm{CO}_{2}$ emission data product: Evaluation and analysis of results. J. Geophys. Res. Atmos. 2014, 119, 10213-10231. [CrossRef]

21. Liang, H.; Tanikawa, H.; Matsuno, Y.; Dong, L. Modeling in-use steel stock in China's buildings and civil engineering infrastructure using time-series of DMSP/OLS nighttime lights. Remote Sens. 2014, 6, 4780-4800. [CrossRef]

22. Shi, K.F.; Yu, B.L.; Huang, Y.X.; Hu, Y.J.; Yin, B.; Chen, Z.Q.; Chen, L.J.; Wu, J.P. Evaluating the ability of NPP-VIIRS nighttime light data to estimate the gross domestic product and the electric power consumption of China at multiple scales: A comparison with dmsp-ols data. Remote Sens. 2014, 6, 1705-1724. [CrossRef]

23. Triantakonstantis, D.; Stathakis, D. Cokriging areal interpolation for estimating economic activity using night-time light satellite data. In Computational Science and Its Applications-Iccsa 2014; Murgante, B., Misra, S., Rocha, A., Torre, C., Rocha, J.G., Falcao, M.I., Taniar, D., Apduhan, B.O., Gervasi, O., Eds.; Springer: Berlin, Germany, 2014; Volume 8582, pp. 243-252.

24. Shi, K.; Chen, Y.; Yu, B.; Xu, T.; Yang, C.; Li, L.; Huang, C.; Chen, Z.; Liu, R.; Wu, J. Detecting spatiotemporal dynamics of global electric power consumption using DMSO/OLS nighttime stable light data. Appl. Energy 2016, 184, 450-463. [CrossRef]

25. Shi, K.F.; Chen, Y.; Yu, B.L.; Xu, T.B.; Chen, Z.Q.; Liu, R.; Li, L.Y.; Wu, J.P. Modeling spatiotemporal $\mathrm{CO}_{2}$ (carbon dioxide) emission dynamics in china from DMSP/OLS nighttime stable light data using panel data analysis. Appl. Energy 2016, 168, 523-533. [CrossRef]

26. Chen, Z.Q.; Yu, B.L.; Hu, Y.J.; Huang, C.; Shi, K.F.; Wu, J.P. Estimating house vacancy rate in metropolitan areas using NPP-VIIRS nighttime light composite data. IEEE J. Sel. Top. Appl. Earth. Obs. Remote Sens. 2015, 8, 2188-2197. [CrossRef]

27. Shi, K.F.; Huang, C.; Yu, B.L.; Yin, B.; Huang, Y.X.; Wu, J.P. Evaluation of NPP-VIIRS night-time light composite data for extracting built-up urban areas. Remote Sens. Lett. 2014, 5, 358-366. [CrossRef]

28. Gao, B.; Huang, Q.; He, C.; Ma, Q. Dynamics of urbanization levels in China from 1992 to 2012: Perspective from DMSP/OLS nighttime light data. Remote Sens. 2015, 7, 1721-1735. [CrossRef]

29. Ma, T.; Zhou, C.H.; Pei, T.; Haynie, S.; Fan, J.F. Quantitative estimation of urbanization dynamics using time series of DMSP/OLS nighttime light data: A comparative case study from China's cities. Remote Sens. Environ. 2012, 124, 99-107. [CrossRef]

30. Yu, B.L.; Shu, S.; Liu, H.X.; Song, W.; Wu, J.P.; Wang, L.; Chen, Z.Q. Object-based spatial cluster analysis of urban landscape pattern using nighttime light satellite images: A case study of China. Int. J. Geogr. Inf. Sci. 2014, 28, 2328-2355. [CrossRef]

31. Zhang, Q.L.; Seto, K.C. Mapping urbanization dynamics at regional and global scales using multi-temporal DMSP/OLS nighttime light data. Remote Sens. Environ. 2011, 115, 2320-2329. [CrossRef]

32. Zhou, Y.Y.; Smith, S.J.; Elvidge, C.D.; Zhao, K.G.; Thomson, A.; Imhoff, M. A cluster-based method to map urban area from DMSP/OLS nightlights. Remote Sens. Environ. 2014, 147, 173-185. [CrossRef]

33. Chand, T.R.K.; Badarinath, K.V.S.; Murthy, M.S.R.; Rajshekhar, G.; Elvidge, C.D.; Tuttle, B.T. Active forest fire monitoring in ttaranchal state, india using multi-temporal DMSP/OLS and MODIS data. Int. J. Remote Sens. 2007, 28, 2123-2132. [CrossRef]

34. Li, X.; Chen, F.; Chen, X. Satellite-observed nighttime light variation as evidence for global armed conflicts. IEEE J. Sel. Top. Appl. Earth. Obs. Remote Sens. 2013, 6, 2302-2315. [CrossRef]

35. Li, X.; Li, D. Can night-time light images play a role in evaluating the syrian crisis? Int. J. Remote Sens. 2014, 35, 6648-6661. [CrossRef] 
36. Bharti, N.; Tatem, A.J.; Ferrari, M.J.; Grais, R.F.; Djibo, A.; Grenfell, B.T. Explaining seasonal fluctuations of measles in niger using nighttime lights imagery. Science 2011, 334, 1424-1427. [CrossRef] [PubMed]

37. Ceola, S.; Laio, F.; Montanari, A. Satellite nighttime lights reveal increasing human exposure to floods worldwide. Geophys. Res. Lett. 2014, 41, 7184-7190. [CrossRef]

38. Imhoff, M.L.; Lawrence, W.T.; Elvidge, C.D.; Paul, T.; Levine, E.; Privalsky, M.V. Using nighttime DMSP/OLS images of city lights to estimate the impact of urban land use on soil resources in the united states. Remote Sens. Environ. 1997, 59, 105-117. [CrossRef]

39. Chalkias, C.; Petrakis, M.; Psiloglou, B.; Lianou, M. Modelling of light pollution in suburban areas using remotely sensed imagery and GIS. J. Environ. Manag. 2006, 79, 57-63. [CrossRef] [PubMed]

40. Butt, M.J. Estimation of light pollution using satellite remote sensing and geographic information system techniques. GISci. Remote Sens. 2012, 49, 609-621. [CrossRef]

41. Han, P.; Huang, J.; Li, R.; Wang, L.; Hu, Y.; Wang, J.; Huang, W. Monitoring trends in light pollution in China based on nighttime satellite imagery. Remote Sens. 2014, 6, 5541-5558. [CrossRef]

42. Kuechly, H.U.; Kyba, C.C.M.; Ruhtz, T.; Lindemann, C.; Wolter, C.; Fischer, J.; Hoelker, F. Aerial survey and spatial analysis of sources of light pollution in Berlin, Germany. Remote Sens. Environ. 2012, 126, 39-50. [CrossRef]

43. Katz, Y.; Levin, N. Quantifying urban light pollution-A comparison between field measurements and EROS-B imagery. Remote Sens. Environ. 2016, 177, 65-77. [CrossRef]

44. Kyba, C.C.M.; Hoelker, F. Do artificially illuminated skies affect biodiversity in nocturnal landscapes? Landsc. Ecol. 2013, 28, 1637-1640. [CrossRef]

45. Bennie, J.; Duffy, J.P.; Davies, T.W.; Correa-Cano, M.E.; Gaston, K.J. Global trends in exposure to light pollution in natural terrestrial ecosystems. Remote Sens. 2015, 7, 2715-2730. [CrossRef]

46. Deng, Y.; Liu, S.H.; Cai, J.M.; Lu, X. Spatial pattern and its evolution of Chinese provincial population and empirical study. Acta Geogr. Sin. 2014, 69, 1473-1486. [CrossRef]

47. Qi, Y.J.; Yang, Y.; Jin, F.J. China's economic development stage and its spatio-temporal evolution: A prefectural-level analysis. Acta Geogr. Sin. 2014, 68, 517-531. [CrossRef]

48. Li, X.; Chen, X.L.; Zhao, Y.S.; Xu, J.; Chen, F.R.; Li, H. Automatic intercalibration of night-time light imagery using robust regression. Remote Sens. Lett. 2013, 4, 46-55. [CrossRef]

49. DMSP-OLS Nighttime Lights Time Series. Available online: https://www.ngdc.noaa.gov/eog/dmsp/ downloadV4composites.html (accessed on 20 August 2016).

50. Elvidge, C.D.; Baugh, K.E.; Dietz, J.B.; Bland, T.; Sutton, P.C.; Kroehl, H.W. Radiance calibration of DMSP/OLS low-light imaging data of human settlements. Remote Sens. Environ. 1999, 68, 77-88. [CrossRef]

51. Wu, J.S.; He, S.B.; Peng, J.; Li, W.F.; Zhong, X.H. Intercalibration of dmsp-ols night-time light data by the invariant region method. Int. J. Remote Sens. 2013, 34, 7356-7368. [CrossRef]

52. Letu, H.; Hara, M.; Tana, G.; Nishio, F. A saturated light correction method for dmsp/ols nighttime satellite imagery. IEEE Geosci. Remote Sens. 2012, 50, 389-396. [CrossRef]

53. Cao, Z.Y.; Wu, Z.F.; Kuang, Y.Q.; Huang, N.S. Correction of DMSP/OLS night-time light images and its application in China. J. Geo-Inf. Sci. 2015, 17, 1092-1102.

54. Elvidge, C.D.; Ziskin, D.; Baugh, K.E.; Tuttle, B.T.; Ghosh, T.; Pack, D.W.; Erwin, E.H.; Zhizhin, M. A fifteen year record of global natural gas flaring derived from satellite data. Energies 2009, 2, 595-622. [CrossRef]

55. Elvidge, C.D.; Hsu, F.C.; Baugh, K.E.; Ghosh, T. National trends in satellite observed lighting: 1992-2012. In Global Urban Monitoring and Assessment Through Earth Observation; Weng, Q., Ed.; CRC Press: Boca Raton, FL, USA, 2014.

56. Liu, Z.F.; He, C.Y.; Zhang, Q.F.; Huang, Q.X.; Yang, Y. Extracting the dynamics of urban expansion in China using DMSP/OLS nighttime light data from 1992 to 2008. Landsc. Urban Plan. 2012, 106, 62-72. [CrossRef]

57. Stow, D.; Petersen, A.; Hope, A.; Engstrom, R.; Coulter, L. Greenness trends of arctic tundra vegetation in the 1990s: Comparison of two NDVI data sets from NOAA AVHRR systems. Int. J. Remote Sens. 2007, 28, 4807-4822. [CrossRef]

58. Ma, M.G.; Wang, J.; Wang, X.M. Advance in the inter-annual variability of vegetation and its relation to climate based on remote sensing. J. Remote Sens. 2006, 10, 421-431. 
59. Yan, E.P.; Lin, H.; Dang, Y.F.; Xia, C.Z. The spatiotemporal changes of vegetation cover in Beijing-Tianjin sandstorm source control region during 2000-2012. Acta Ecol. Sin. 2014, 34, 5007-5020.

60. Sun, Y.L.; Yang, Y.L.; Zhang, Y.; Wang, Z.L. Assessing vegetation dynamics and their relationships with climatic variability in northern china. Phys. Chem. Earth 2015, 87-88, 79-86. [CrossRef]

61. Light pollution in Hong Kong. Available online: https://en.wikipedia.org/wiki/Light_pollution_in_Hong_ Kong (accessed on 15 September 2016).

(C) 2017 by the authors; licensee MDPI, Basel, Switzerland. This article is an open access article distributed under the terms and conditions of the Creative Commons Attribution (CC BY) license (http:/ / creativecommons.org/licenses/by/4.0/). 